\title{
PENGALAMAN CAREGIVER DALAM MERAWAT PASIEN PALIATIF DI PANTI WERDHA TULUS KASIH
}

\author{
Putri Raissa Hamidah, Nurhayati Siagian
}

Fakultas Ilmu Keperawatan, Universitas Advent Indonesia, Jl. Kolonel Masturi No. 288, Parongpong, Bandung Barat

\author{
E mail : raissaputri30@gmail.com
}

\begin{abstract}
Abstrak
Pasien paliatif lansia di Panti Werdha sangat bergantung pada pertolongan orang lain untuk perawatan dalam memenuhi kebutuhan dan menjalan aktivitas sehari-hari, sehingga pasien didampingi oleh Caregiver. Penelitian ini bertujuan untuk mencari tahu pengalaman yang dirasakan oleh para Caregiver dalam merawat pasien paliatif di Panti Werdha Tulus Kasih. Metode yang digunakan menggunakan metode kualitatif, dengan mengumpulkan data menggunakan metode wawancara dengan panduan berstruktur serta menggunakan teknik purposive sampling yang meilbatkan empat partisipan. Penelitian ini menghasilan enam tema yang meliputi: pemahaman para Caregiver mengenai pasien paliatif, apa saja kebutuhan pasien paliatif, kesulitan apa saja yang dialami oleh Caregiver saat memberikan tindakan pada pasien paliatif lansia, respons Caregiver saat mengalami kesulitan merawat pasien paliatif, upaya apa saja yang dilakukan oleh Caregiver saat mengalami kesulitan merawat pasien paliatif, dan upaya yang dilakukan Caregiver dalam meningkatkan tindakan bagi pasien paliatif. Sebaiknya ada tenaga perawat professional untuk mendampingi para Caregiver karena Caregiver hanya memberikan bantuan bagi pasien untuk melakukan aktivitas sehari-hari dan memberikan perhatian. Caregiver harus ikut dalam seminar dan pelatihan untuk mengupgrade pengetahuan serta mengetahui trend tentang cara merawat pasien paliatif. Caregiver memberikan pelayanan melalui pendekatan personal untuk peningkatan taraf hidup penderita atau pasien \& keluarganya. Caregiver juga memberi pelayanan 24 jam sehari untuk memberikan dukungan, bimbingan dan bantuan bagi pasien paliatif. Para Caregiver merasakakn tekanan beban dalam menghadapi kesulitan untuk merawat pasien paliatif, namun dengan pengalaman yang sudah cukup lama para Caregiver dapat mengatasi dengan mudah.
\end{abstract}

Keyword : Paliatif, Panti Werdha, Caregiver

\begin{abstract}
Elderly palliative patients at the Nursing Home are very dependent on the help of others for care to meet their needs and carry out their daily activities, so that patients are accompanied by a Caregiver. This reasearch was to ascertain an expertises felt by Caregivers in caring for palliative patients at the Tulus Kasih Home. This research uses qualitative methods, data collection using interview methods with structured guides, and a purposive sampling technique that includes four participants. The result of this study covered six themes: the Caregiver's understanding of palliative patients, what the palliative patients needs, what difficulties the Caregiver experiences when giving action to elderly palliative patients, the Caregiver's response when having difficulty caring for palliative patients, what efforts are made by the Caregiver when having difficulty caring for palliative patients, and the efforts made by the Caregiver in increasing the action for palliative patients. It is better if professional nurses are to assist Caregivers because Caregivers only provide assistance for patients to carry out daily activities and provide attention. Caregivers should participate in seminars and training to upgrade the knowledge and find out about how to care for palliative patients. Caregiver offer services through a personal approach improving the standard of life of sufferers or patients \& their families. The Caregiver also provides services 24 hours a day to provide support, guidance, and palliative patients assistance. The Caregiver feel the pressure of the burden in facing the difficulties of caring for palliative patients, but with much more experience, the Caregivers can handle it easily.
\end{abstract}

Keyword: Palliative, Panti Werdha, Caregiver 


\section{Pendahuluan}

Banyaknya tugas yang dikerjakan oleh Caregiver dapat menimbulkan beban yang dirasakan oleh Caregiver. Menurut Sukmarini (2009) ada dua beban yang dirasakan oleh Caregiver selama merawat pasien paliatif, yaitu beban subjektif dan beban objektif. Beban subjektif yang dirasakan Caregiver selama merawat pasien adalah respon psikologis Caregiver selama berperan dalam merawat pasien. Beban objektif adalah masalah dalam pekerjaan merawat pasien maupun masalah keuangan.

Caregiver melakukan tugas perawatan kepada pasien paliatif dalam 4 kategori :

a. Physical Care : seperti membantu pasien mengganti pakaian dan dan memberi makan pasien.

b. Social Care : seperti bertindak sebagai informan dari dunia luar di luar perawatan.

c. Emotional Care : seperti menunjukkan cinta dan kasih saying kepada pasien.

d. Quality Care : seperti berurusan dengan masalah yang timbul pada pasien.

Caregiver yang merawat pasien paliatif dapat merasakan kelelahan emosional yang kemudian menimbulkan menurunnya imunitas Caregiver dan dapat memengaruhi kesehatan Caregiver. Namun, pengalaman dan lama kerja juga menentukan baik buruknya mekanisme koping Caregiver.

World Health Organization (2016) memberikan gambaran mengenai perkiraan total lansia, yaitu pada tahun 2020 akan meraih total angka 28.800.000 atau $(11,34 \%)$ dari jumlah populasi. Dinegara Indonesia sendiri jumlah data dari lansia yang berusia diatas 65 tahun, dilaporkan telah mencapai 12.740 .265 orang. Laporan ini dilaporkan badan pusat data \& informasi Kementerian Kesehatan Republik Indonesia tahun 2014. Banyak keluarga para lansia yang merasa tidak mampu merawat lansia, sehingga mereka memilih untuk meninggalkan lansia di Panti Werdha. Alasan para anak melakukannya adalah karena mereka sangat sibuk dengan kegiatan mereka sehingga tidak mampu untuk mengurus orang tua mereka. Selainitu, banyaknya permasalahan yang muncul dalam kehidupan orang tua dapat menyebabkan anak menjadi kewalahan dan kesulitan untuk menjalani kehidupan berkeluarga. Maka dari itu, alasan-alasan yang muncul serta pertimbangan untuk membahagiakan kedua orang tuanya, anak terpaksa harus meninggalkan orang tuanya dan menitipkan orang tua mereka ke Panti Werdha. Kementerian Sosial Indonesia mendefinisikan Panti Werdha sebagai tempat yang menampung para lanjut usia dengan memberikan pelayanan, sehingga mereka merasa aman dan nyaman tanpa harus merasa cemas atau khawatir menghadapi masa tua.

Tahap akhir dari sebuah perkembangan hidup manusia dapat dikatakan sebagai lansia. Menurut pendapat Syam'ani (2011) Turunnya fungsi tubuh yang berakibat lemahnya fungsi tubuh manusia merupakan identifikasi tubuh lansia di Indonesia. Karena penurunan fungsi kognitif dan penyakit yang dialami maka kemampuan lansia untuk melakukan aktivitas normal menjadi menurun. Orang tua mudah terserang penyakit yang tidak bisa disembuhkan yang mengancam nyawa atau yang disebut penyakit paliatif. Pasien paliatif lansia yang tinggal di Panti Werdha diurus oleh Caregiver. Awad \& Voruganti (2008) menjelaskan bahwa Caregiver merupakan seorang individu secara general merawat dan mendukung individu lain (pasien) dalam kehidupannya. Caregiver merupakan sebuah lembaga penyedia layanan kesehatan anak, dewasa \& lansia yang telah lemah tubuh dan fungsi organnya (Stanley M, 2006). Menurut Awad \& Voruganti, (2008: 87) mengatakan Seorang Caregiver ialah seseorang yang mengasuh atau merawat serta mendukung pasien lainnya.

Kung (2003: 3), berpendapat bahwa seorang Caregiver berperan untuk memberi dukungan, merawat pasien seperti (memandikan, memakaikan baju, menyiapkan makan, mempersiapkan obat), mengatur keuangan, memberikan keputusan terhadap perawatan \& berkoordinasi dengan pelayanan kesehatan formal. Definisi perawatan paliataif menurut World Health Organization (2016) adalah sebagai pendekatan tim interdisipliner sebagai peningkatkan quality of life penderita serta keluarga dengan penyakit yang mengancam jiwa dengan cara identifikasi awal, penilaian, pengobatan nyeri dan masalah tubuh, psikologis, dan spiritual. Membutuhkan $\geq 20.000 .000$ orang per tahunnya dengan perawatan paliatif end of life fase (Worldwide Palliative Care Alliance, 2014). Didalam penelitian Long et al.,(2016); Round, (2016); Sadler, (2015) menyatakan bahwa end of life fase sebagai fokus perawatan paliatif. Pengalaman yang berbeda dapat dialami oleh Caregiver dalam merawat pasien paliatif di Panti Werdha.

Panti Werdha Tulus Kasih adalah Panti Werdha yang terletak di Bandung, Jawa Barat. Panti Werdha Tulus kasih didirikan sejak 1 February 2012 dengan jumlah Caregiver sebanyak 10 orang.

\section{Metode}

Penelitian ini menrupakan penelitian kualitatif dengan metode fenomelnologi. Metodologi sebagai proses, prinsip, dan prosedur yang digunakan untuk mendekati 
problem dan mencari jawaban (Mulyana dalam Prasanti 2018). Interpretative Phenomenological Analysis atau IPA digunakan untuk menganalisis datanya. Jika peneliti menggunakan teknik ini maka teknik ini dianggap sesuai, karena di dalam teknik ini akan melakukan penelitian seseorang human akan mengerti kejadian dalam kehidupnya sebagai sesuatu yang natual (Smith, Flower \& Larkin, 2009). Berdasarkan hasil research dari (Smith, Flowers \& Larkin, 2009) dengan memilih subyek penelitian Interpretative Phenomenological Analysis berdasarkan pada teknik purposive sampling. Purposive sampling dipilih setelah melakukan wawancara lapang untuk memastikan orang-orang yang telah dipilih untuk sebuah penelitian memiliki kriteria yang sesuai dengan penelitian menurut (Sugiyono, 2009).

Metode wawancara mendalam dengan semi terstruktur digunakan untuk mengumpulkan data oleh peneliti. Pertama peneliti akan melakukan pengembangan kerangka pokok bahasan kemudian menyampaikannya kepada partisipan berupa pertanyaan wawancara. Alur dalam wawancara dibuat senyaman mungkin dan terbuka pada partisipan. Kemudian pertanyaan dikonsep sedemikian rupa sehingga tidak langsung terarah pada pertanyaan penelitian. Sebelum hari wawancara peneliti akan meminta ijin pada narasumber untuk merekamnya. Selanjutnya, jawaban narasumber dalam rekaman akan didengarkan dan diubah menjadi bentuk tertulis (transkrip).

Penggunaan interpretative phenomenological analysis digunakan dalam penelitian ini. Langkah-langkah untuk menganalisis data dengan menggunakan teknik ini antara lain:

1. Melakukan pembacaan hasil wawancara berkali-kali.

Didalam proses ini melakukan pembacaan hasil wawancara berupa transkip secara berulang-ulang.

2. Melakukan Pencatatan awal (initial noting). Didalam tahap ini yang harus adalah peninjauan ulang kata serta bahasa pada tahap eksplorasi. catatan atau komentar eksploratoris.

3. Munculnya tematik harus dilakukan pengembangan (developing emergent themes)

4. Melakukan analisis antara hubungan dengan tema

5. Melakukan perpindahan untuk kasus berikutnya

6. Menentukan pola-pola yang sama antar kasus

7. Menentukan dan identifikasi deskripsi induk tema

\section{Hasil Penelitian}

Hasil penelitian ini didapatkan dengan wawancara kepada empat partisipan dengan lama kerja lebih dari satu tahun dan didapatkan enam tema, yaitu : pemahaman para Caregiver mengenai pasien paliatif, apa saja kebutuhan pasien paliatif, kesulitan apa saja yang dialami oleh Caregiver saat memberikan tindakan pada pasien paliatif lansia, respons Caregiver saat mengalami kesulitan merawat pasien paliatif, upaya apa saja yang dilakukan oleh Caregiver saat mengalami kesulitan merawat pasien paliatif, dan upaya yang dilakukan Caregiver dalam meningkatkan tindakan bagi pasien paliatif. Berikut dibawah ini adalah rincian dari keenam tema yang dibahas :

\section{Pemahaman Caregiver mengenai pasien paliatif}

Pemahaman para Caregiver mengenai pasien paliatif adalah hal dasar yang perlu dipahami oleh setiap Caregiver yang merawat pasien paliatif untuk mengetahui pengetahuan dari arti paliatif itu seperti apa. Pembahasannya adalah sebegai berikut, yaitu :

“..menurut saya ya paliatif itu penyakit yang harus minum obat..”. (P3)

“..paliatif itu apa ya teh. Ya pokoknya yang udah sakit sekali, minum obat terus, gak sembuh...” (P1)

“..penyakit yang sering dialami oleh orang tua...” (P2)

“..penyakit yang udah gak bisa sembuh lagu teh, jadi minum obat juga kayak cuma buat ngurangin gejala aja tapi gak bikin sembuh.." (P4)

Pernyataan diatas menunjukan bahwa sebagian besar partisipan tidak begitu memahami maksud dari pengertian pasien paliatif secara detail dan jelas, para partisipan hanya memahami gambaran umum dari pengertian paliatif itu dari pengalaman selama dilapangan, bagi partisipan pengertian dari paliatif itu yaitu penyakit yang sering dialami oleh lansia yang penyakitnya sudah tidak akan bisa sembuh dan harus selalu meminum obat untuk mengurangi gejala penyakit bukan untuk menyembuhkan penyakitnya.

\section{Kebutuhan para pasien paliatif}

Tema diatas bermaksud untuk menjelaskan apa saja yang dibutuhkan oleh pasien paliatif dalam menjalankan kehidupan sehari-hari, Berikut akan dibahas berdasarkan tema tersebut:

“..yang paling pertama menurut saya sih semangat teh, soalnya kalau pasien semangat itu juga ngebantu ningkatin kesehatannya pasien. Kalau disini kita suka 
karokean bareng biar pasien-pasien semangat terus gak bosen juga.." (P1)

“..disini diadain pengajian bagi yang muslim satu bulan dua kali teh. Soalnya spiritual penting buat pasien, kalau pasien rajin ibadah pasien jadi tau kalau yang hidup pada akhirnya pasti pulang lagi ke Allah. Jadinya mereka lebih berserah diri buat menghadapi penyakitnya.." (P4)

“..semua pasien kita mandiin teh, kita juga gantiin pampers nya. Soalnya kebersihan diri penting, ratarata mereka udah susah buat mandi sendiri terus kita juga takut mereka jatoh jadi kita mandiin aja. Contohnya kayak pasien yang stroke, mereka kan udah gak bisa apa-apa jadi harus kita bantu kebersihannya terus kita mika miki juga biar gak decubitus. Kalau yang bisa gerak sih kita bantu juga tapi sambal kita ajarin sama arahin juga gimana caranya mandi yang bener.." (P2)

Peryataan diatas dapat disimpulkan bahwa kebutuhan pasien paliatif menurut partisipan yaitu dari aspek psikologis untuk tetap terus semangat dalam menjalankan kehidupan sehari-hari, karena dari sikap semangat pasien dalam menjalankan aktivitas akan membantu meningkatkan kesehatan pikiran. Dari aspek spiritual, kegiatan spiritual perlu dilakukan untuk mengingatkan setiap pasien untuk lebih menerima dan lebih ikhlas dalam penyakit yang dialaminya. Lalu dari aspek kebersiha fisik, semua pasien paliatif sangat perlu diperhatikan dalam tingkatan kebersihannya karena banyak pasien paliatif yang sudah tidak sanggup untuk memperhatikan kebersihan dirinya sendiri.

\section{Kesulitan yang dialami saat memberikan tindakan pada pasien paliatif lansia}

Kesulitan yang sering dialamai oleh Caregiver saat memberikan tindakan pada pasien paliatif adalah dimana tindakan untuk mengidentifikasi hal yang akan menghambat dalam pemberian perawatan untuk pasien.

“..kalau kesulitan nya ya kan disini pasien nya udah pada tua ya teh, jadi kayak anak-anak lagi suka susah diatur.." (P1)

“..kesulitannya ya kayak contohnya yang pasien Alzheimer. Mereka kan daya ingat nya udah parah banget jadinya lupa terus kan. Jadi harus kita ingetin terus dan mereka juga rata-rata susah percaya sama orang teh, jadi suka ketus gitu kalau mau kita bantuin.Mereka juga biasanya aktif pas malem, jadi kita begadang buat bujuk biar mereka mau tidur.." (P3) “..kesulitan nya kayak kalau mau angkat pasien stroke, mereka kan bener-bener bertumpu sama kita. Jadi kita harus kuat kalau mau angkat pasien nya.." (P4)

Pernyataan yang diberikan oleh para partisipan dapat disimpulkan bahwa kebanyakan dari pasien paliatif yang mayoritas lansia memiliki prilaku yang sulit diatur, memiliki daya ingat yang sudah samar-samar menjadi mudah lupa, dan pasien yang sudah sangat sulit beraktifitas biasanya diperhatikan dengan lebih oleh para perawat untuk pindah dari posisi tertentu ke posisi lainnya. Sehingga partisipan perlu tenaga lebih untuk membantu aktifitas pasien.

\section{Respons Caregiver saat mengalami kesulitan}

Respons Caregiver pada saat mengalami kesulitan dalam mengurus pasien adalah untuk mengetahui sebuah reaksi partisipan dalam menanggapi setiap pasien paliatif.

“..ya kadang bete, jengkel juga. Tapi saya selalu istighfar dan inget kalau mereka itu harus dibantu dan saya ngerasanya mereka udah kayak orang tua saya sendiri. Kalau saya udah istighfar saya lebih sabar lagi..” (P2)

“..saya sih kalau misalnya ada pasien yang susah dikasih tau, saya biasanya ngehibur diri nyanyi-nyanyi aja teh biar gak bete. Senengnya kalau saya nyanyi biasanya ada pasien yang ikutan nyanyi juga.. " (P1)

Dari pernyataan diatas para partisipan merasakan kesal layaknya manusia pada umumnya, namun para partisipan sudah merasa dan menganggap para pasien seperti keluarganya sendiri, jadi partisipan sudah menaruh perasaan terhadap pasien dan lebih bersabar dalam merawat para pasien.

\section{Upaya yang dilakukan oleh Caregiver untuk menangani kesulitan}

Upaya yang dilakukan oleh para Caregiver untuk menangani kesulitan dalam merawat setiap pasien adalah tindakan untuk menangani kesulitan yang terjadi sehari-hari. Berikut akan dibahas menurut para partisipan:

"..kalau misalnya pasien nya gamau makan ya saya bujuk teh sampai pasien nya mau makan..” (P3)

“..pas saya mau angkat pasien stroke saya coba angkat dulu semampu saya, kalau saya gak sanggup saya panggil temen saya buat bantu angkat.." (P4)

“..mereka kadang susah banget teh kalau harus mandi. Jadi kadang saya kelitikin aja atau saya tanya kenapa gak mau mandi, terus saya bujuk sampai akhirnya mandi.." (P2) 
Dari pernyataan diatas menunjukan bahwa kebanyakan partisipan menangani kesulitan dengan cara personal dan lebih pendekatan personal terhadap pasien yang dijelaskan oleh partisipan bahwa mereka lebih sering melakukan bujuk, meminta bantuan perawat lainnya, dan candaan.

\section{Upaya yang dilakukan Caregiver dalam meningkatkan tindakan bagi pasien paliatif}

Upaya dalam meningkatkan tindakan para Caregiver untuk merawat para pasien adalah hasil akhir dari tema untuk mengetahui apa yang dilakukan para perawat dalam meningkatan tindakan-tindakan untuk mengurus para pasien.

“.caranya ya Caregiverdisini harus saling kerjasama teh. Kalau ngurus pasien terus kita gak kerja sama ya repot.." (P1)

\section{"kita juga ada manggil fisioterapi buat pasien teh.." (P3)}

Pernyataan yang diberikan dari setiap partisipan bahwa para perawat selalu bekerja sama dalam mengurus pasien untuk meningkatkan setiap tindakan mereka, dan menggunakan jasa fisioterapi untuk memenuhi kebutuhan pasien paliatif.

\section{Pembahasan}

\section{Pemahaman Caregiver mengenai pasien paliatif}

Dari tema diatas, bisa diketahui bahwa tiga dari empat partisipan belum mengetahui apa itu paliatif secara detail. Menurut penelitian yang dilakukan oleh Agnes Trigiarti (2018), menunjukan bahwa pengetahuan dapat dipengaruhi oleh lama kerja dan pengalaman. Hal ini juga sesuai dengan penelitian Alshaik (2015) yaitu perawat mendapatkan pengetahuan mengenai perawatan paliatif melalui pengalaman dan tanpa disadari perawat melakukan perawatan paliatif dalam praktek sehari-hari Paliatif adalah suatu keadaan dimana seseorang menderita penyakit menuju kematian dan sudah tidak bisa diobati lagi dengan pengobatan kuratif, obat hanya berfungsi untuk mengurangi gejala dan bukan untuk menyembuhkan penyakit. Menurut WHO (2016) cara yang dapat dilakukan untuk meningkatkan kualitas hidup pasien beserta keluarganya untuk menghadapi sakit yang mengancam jiwa mereka dapat dilakukan dengan cara meringankan penderitaan rasa sakit melalui identifikasi dini, pengkajian yang sempurna, dan penatalaksanaan nyeri serta masalah lainnya baik fisik, psikologis, social atau spiritual dengan perawatan paliatif.

\section{Kebutuhan para pasien paliatif}

Sebagai Caregiver, kita harus memberikan perawatan holistic bagi pasien plaitaif. Kegiatan-kegiatan tersebut akan berpengaruh pada waktu, emosi dan juga psikologi. Selanjutnya akan mempengaruhi stress pada Caregiver (Losada et al, 2009). Menurut Campbell (2013) menjelaskan bahwa dilihat dari perspektif keperawatan, masalah-masalah yang muncul terhadap pasien paliatif adalah masalah psikologi, masalah hubungan sosial, konsep diri, masalah dukungan keluarga serta masalah pada aspek spiritual atau keagamaan. Menurut sebuah hasil penelitian dari Milligan (2011) mengklaim "sekarat dan kematian merupakan kondisi dimana pasien mengalami penderitaan rohani serta berakibat penderitaan dan usaha kerja spiritual, seperti menyelesaikan masalah spiritual serta berdamai dengan realitas kematian secara pribadi”. Maka dari itu kebutuhan spiritual paisen harus dipenuhi tanpa mengesampingkan kebutuhan fisik, social dan psikologis pasien karena caregiving paliatif geriatrik bertujuan untuk meringankan individu lanjut usia dari rasa sakit dan penderitaan yang mereka alami melalui pendekatan biopsikososial-spiritual (Dane \& Moore, 2006; Chandrana, Corbina, \& Shillamb, 2016).

Pasien paliatif memiliki beberapa masalah seperti kebutuhan fisik, psikologis, social dan spiritual yang harus diatasi. Nyeri merupakan permasalah fisik yang muncul dan dikeluhkan oleh penderita paliatif. Nyeri ini merupakan gejala emosional dan sensorik yang tidak menyenangkan yang disebabkan oleh rusaknya jaringan aktual secara tiba-tiba dari intensitas ringan hingga parah. Selain nyeri, terdapat gejala fisik lainnya yang ditunjukkan oleh pasien paliatif antara lain perubahan penglihatan, pendengaran, nutrisi, cairan tubuh, eliminasi, kulit, tanda vital, dan mobilisasi. Perawat harus mampu mengenali perubahan pada tubuh pasien, menderita berbagai gejala yang menyakitkan berbulan-bulan pasca kematiannya. Dalam hal ini seorang perawat harus tanggap pada perubahan fisik yang terjadi pada pasien terminal karena peristiwa itu menyebabkan ketidaknyamanan serta penurunan kemmapuan pasien dalam pemeliharaan diri menurut pendapat (Smeltzer \& Suzanne, 2014).

Menurut pendapat Misgiyanto \& Susilawati (2014) Penderita paliatif sering mengalami kecemasan. Rasa cemas itu disebabkan karena diagnosa penyakitnya yang mengakibatkan pengidap merasa ketakutan sehingga mengakibatkan penderita dan anggota keluarga merasa cemas. Rasa cemas dapat membuat seseorang menjadi khawatir dan respon otonom 
memberi rasa takut akan antisipasi bahaya (Nanda, 2015). Ini adalah sinyal urgensi terhadap seseorang serta mampukah individu mengatasinya.

Banyak pasien paliatif merasa malu dengan penurunan fisiknya dan hal itu membuat mereka membatasi social mereka. Masalah social juga berhubungan dengan masalah emosional dan psikologis pasien. Menurut Kelliat (2006) seseorang individu dapat mengalami keadaan penurunan hingga tidak dapat berinteraksi dengan sekelilingnya, dapat disebabkan karena rasa insecure pada penderita, unacceptable, kesepian, dan tidak dapat menjalin hubungan yang berarti dengan orang lain.

Distress spiritual adalah masalah lain yang sering muncul pada pasien paliatif. Menurut Hamid (2008) kemampuan yang rusak saat mengalami dan mengintegrasikan arti serta tujuan hidup seseorang, orang lain, seni, musik, literature, alam dan kekuatan yang lebih besar dari dirinya adalah distress spiritual.

\section{Kesulitan yang dialami saat memberikan tindakan pada pasien paliatif lansia}

Caregiver membutuhkan tenaga ekstra saat memberi perawatan kepada pasien paliatif karena sebagian besar pasien kondisi fisik nya sudah menurun.

Keterampilan dan pengetahuan Caregiver merupakan hal yang penting untuk merawat pasien paliatif. Davies et al (2008) menyatakan bahwa "hambatan dalam memberikan perawatan terminal yaitu akses terbatas penyedia perawatan terminal, ketidakpastian dalam prognosis dan hasil pengobatan dan kurangnya komunikasi serta hambatan dari pemberi perawatan". Lemahnya pendidikan dan pelatihan skill merupakan sebuah penghalang untuk perawatan terminal (Ogle et al., 2003).

Caregiver harus dapat menjalin komunikasi yang baik dengan pasien karena pelayanan dapat berjalan dengan baik apabila terdapat hubungan saling percaya antara pasien dengan Caregiver. Agar tercapainya pemberian pelayanan dengan baik, Caregiver harus membina hubungan terbuka antara pasien, keluarga dan layanan lainnya.

\section{Respons Caregiver saat mengalami kesulitan merawat pasien paliatif}

Caregiver terkadang merasa lelah dan jengkel karena pasien paliatif lansia memerlukan banyak bantuan karena sebagian besar dari mereka sudah tidak bisa membantu dirinya sendiri untuk melakukan aktivitas sehari-hari. Adanya keterbatasan tersebut menyebabkan Caregiver kelehan karena pasien membutuhkan bantuan dari orang lain untuk melakukan berbagai aktivitas sehari-hari. Menurut Neugaard,dkk (2008) bantuan dari orang lain sering disebut Caregiver, untuk melakukan perawatan diri dan pemenuhan kebutuhan secara umum. Semakin lemah dan kronis penyakit pasien maka semakin tinggi beban yang dialami Caregiver (Gbiri, Olawale, \& Isaac, 2015).

Menurut Arksey, dkk (2005) hal-hal atau tugas yang dapat dilakukan oleh informal atau family Caregiver adalah membantu dalam perawatan personal yang meliputi berpakaian, mandi, dan urusan toilet; membantu dalam mobilitas, seperti berjalan atau membantu membaringkan ditempat tidur; melakukan tugas-tugas keperawatan, termasuk pengawasan obat atau mengganti pakaian; mengawasi dan memonitor recipient; memberikan dukungan emosional; sebagai teman dekat bagi recipient; melakukan tugas-tugas praktis rumah tangga, termasuk memasak, berbelanja, pekerjaan rumah; serta membantu masalah-masalah finansial dan kerja administratif. Hal yang dilakukan oleh Caregiver formal (tidak ada hubungan keluarga) sama dengan yang dilakukan oleh informal Caregiver (ada hubungan keluarga)

Apabila kualitas hidup Caregiver baik, maka baik pula kualitas perawatan yang diberikan pada pasien. Menurut Weitzner (1999) kualitas hidup Caregiver didefinisikan sebagai hasil dari perawatan kesehatan dan rehabilitasi atau dapat disebut dengan status kesehatan yang mencakup kesehatan fisik, kondisi emosi, kehidupan sosial, dan keadaan finansial. Konsep kualitas hidup sering digunakan sebagai indikator keberhasilan dari berbagai layanan kesehatan karena dianggap dapat berpengaruh penting pada kesehatan seseorang (Caquen-Urizar, 2009, dalam Kate, 2013). Caregiver menjadi kurang mampu dan kurang mau untuk memberikan perawatan dengan kualitas yang baik pada pasien paliatif disebabkan oleh kualitas hidup yang buruk

\section{Upaya yang dilakukan oleh Caregiver untuk menangani kesulitan}

Caregiver berupaya menangani kesulitan dengan cara refleksi diri bahwa pengetahuan dan sikap Caregiver terhadap pasien sangat berpengaruh bagi kesehatan pasien. Caregiver berusaha dan harus mempunyai kemampuan komunikasi terapeutik yang baik untuk memberikan bantuan dan support kepada pasien. Didalam perawatan pasien komunikasi terapeutik adalah sebuah elemen penting sebagai pelayanan perawatan paliatif. Menurut Hasan dan Rasyid (2016) mereka menjelaskan bahwa yang menjadi dasar komunikasi terapeutik sebagai kepastian pengobatan, hasil kesehatan yang positif, kepatuhan pasien dan kualitas perawatan secara keseluruhan. 
Dalam memberikan perawatan paliatif dibutuhkan kolaborasi antar tim kesehatan agar perawatan yang idberikan bagi pasien paliatif lebih maksimal.

\section{Upaya yang dilakukan Caregiver dalam meningkatkan tindakan bagi pasien paliatif}

Caregiver harus mengikuti pelatihan perawatan paliatif, karena menurut Joeharno (2011) pelatihan yang dilakukan untuk tenaga medis atau kesehatan memberikan dampak dalam meningkatan pengetahuan sebagai upaya peningkatan pelayanan untuk pasien. Pelatihan diperlukan karena terkadang Caregiver harus mengambil keputusan bagia pasien paliatif.

Diperlukan tenaga professional untuk mendampingi Caregiver karena Caregiver tidak memberikan perawatan medis dan seseorang yang merawat pasien paliatif harus memahami suatu tanda dan gejala fisik yang dialami oleh pasien paliatif. Tenaga professional harus mampu melakukan pengkajian, pendokumentasian dan membuat rencana perawatan kepada pasien paliatif. Menurut (De Roo et al., 2013; Dy et al., 2015) Physical Aspect Of Care adalah cara yang dilakukan untuk mengukur dan mendokumentasikan rasa nyeri dan gejala lainnya yang muncul. Contohnya adalah penilaian, pengelolaaan gejala atau efek samping yang terjadi pada permasalahan fisik pasien.

\section{Kesimpulan}

Berdasarkan hasil penelitian di Panti Werdha Tulus Kasih, terlihat peran Caregiver sangat membantu pasien paliatif di Panti Werdha Tulus Kasih. Caregiver memberikan pelayanan melalui pendekatan personal untuk peningkatan taraf hidup penderita atau pasien $\&$ keluarganya. Caregiver juga memberi pelayanan 24 jam sehari untuk memberikan dukungan, bimbingan dan bantuan bagi pasien paliatif. Para Caregiver merasakakn tekanan beban dalam menghadapi kesulitan untuk merawat pasien paliatif, namun dengan pengalaman yang sudah cukup lama para Caregiver dapat mengatasi dengan mudah. Caregiver memfokuskan perawatan terhadap kulaitas hidup, termasuk control gejala yang tepat dengan memperhatikan aspek biopsikospiritual yang sangat penting untuk menjalankan kegiatan harian pasien. Caregiver menerapkan komunikasi terbuka dan Panti Werdha Tulus Kasih memberikan perawatan fisioterapi professional Kesehatan bagi pasien paliatif.. Caregiver selalu menghargai hak-hak pasien dalam menentukan pilihan, memberikan kenyamanan, agar pasien tetap merasa bahwa keeksistensiannya ada.

\section{Saran}

Dilihat dari hasil wawancara, masih banyak factor yang membuat kurangnya kualitas Caregiver dari segi pegetahuan tentang perawatan paliatif. Sebaiknya ada tenaga perawat professional untuk mendampingi para Caregiver karena Caregiver hanya memberikan bantuan bagi pasien untuk melakukan aktivitas seharihari dan memberikan perhatian. Caregiver tidak memiliki wewenang untuk melakukan perawatan medis. Maka dari itu dibutuhkan tenaga professional untuk mendampingi para Caregiver dalam memberikan perawatan agar pasien mendapatkan perawatan yang holistic.

Caregiver harus ikut dalam seminar dan pelatihan untuk mengupgrade pengetahuan serta mengetahui trend tentang cara merawat pasien paliatif. . Sesuai dengan pedoman meningkatkan kualitas pelayanan paliatif menurut National Consensus Project For Quality Palliative Care (NCP,2013).

Ada beberapa pedoman keperawatan paliatif yang dapat di pelajari untuk meningkatkan kualitas Caregiverdi Panti Werdha Tulus Kasih, yang akan dibahas dibawah ini:

1. Structure and proses of care, adalah kegiatan yang dilakukan dengan menyelenggarakan pelatihan dan pendidikan bagi para professional paliatif dalam memberikan perawatan yang berkesinambungan pada pasien dan keluarga (Dy et al, 2015).

2. Physical aspect of care, tujuan melakukan ini adalah sebagai upaya untuk mengukur dan mendokumentasikan rasa nyeri dan gejala lain, yaitu menilai, mengelola gejala dan efek samping yang terjadi pada masalah fisik pada pasien (Dy et al, 2015).

3. Psychological and psychiatric aspect of care, adalah sebuah langkah untuk melihat bagaimana kondisi psikologis pasien \& keluarga, yaitu dengan melakukan pengukuran, dokumentasi, pengelolaan kecemasan \& gejala psikologi lainnya (Dy et al, 2015)

4. Social aspect of care, sebagai langkah diskusi berbagai sumber informasi, berdiskusi perihal perawatan serta social supproting yang komperhensif (Dee Roo et al, 2013).

5. Spiritual, Religious, and Existential aspect of care, adalah langkah sebagai penyedia \& fasilitator diskusi yang berkaitan dengan kebutuhan spiritual pasien dan (Dy et al, 2015)

6. Care of the parient at end of life, adalah langkah tentang bagaimana mengetahui lebih lanjut sebuah kesiapan untuk menghadapi kematian dan duka cita keluarga yang ditinggalkan setelah kematian (De Roo et al, 2013) 
7. Ethical and legal aspect of care, adalah sebuah langkah rencana dengan memperhatikan preferensi pasien \& keluarga yang menerima pelayanan tanpa adanya pelanggaran terhadap norma dan aturan yang adaDy et al, 2015).

Semua perawat dan Caregiver harus mengerti hokum aspek paliatif dan mencari pakar hokum jika diperlukan.

Pedoman diatas dapat di terapkan sebagai acuan untuk meningkatkan kualitas Caregiver dari aspek pengetahuan, pelayanan dan tindakan dalam memberikan perawatan paliatif dan membuat perawat serta Caregiver menjadi lebih professional terhadap perannya.

\section{Daftar Pustaka}

(WHO), W. H. (2016). Planning and implementing palliative care services; a guide for programme managers. WHO Library Cataloguing, 1-79.

A, L., Perez-Penaranda, A, R.-S. E., MA, G.-M., C, B.R., IR, R.-C., . . . L, G.-O. (2009). Leisure and distress in Caregivers for elderly patients. Archive of Gerontology and Geriatrics, 50 : 347-350.

$\begin{array}{ccc}\text { Afriansyah, A., \& } & \text { Santoso, M. } & \text { B. } \\ \text { PELAYANAN } & \text { PANTI } & \text { WERDHA } \\ \text { TERHADAP } & \text { ADAPTASI } & \text { LANSIA. } \\ \text { Responsive, 191-192. } & \end{array}$

Anggraini, S., Ningsih, N., \& Jaji. (2019). HUBUNGAN ANTARA DUKUNGAN KELUARGA DENGAN SELF ESTEEM PADA PERAWATAN PALIATIF PASIEN KANKER SERVIKS. Conference Unsri, 165.

Ariesti, E., Ratnawati, R., \& Lestari, R. (2018). PHENOMENOLOGY STUDY: CAREGIVER EXPERIENCE IN NURSING ELDERLY . Jurnal Ilmu Keperawatan Vol. 6, No. 1, 30-39.

Ariska, Y. N., Handayani, P. A., \& Hartati, E. (2020). Faktor yang Berhubungan dengan Beban Caregiver dalam Merawat Keluarga yang Mengalami Stroke. Journal of Holistic Nursing and Health Science Volume 3, No. 1, 53.

Awad, A., \& Voruganti, L. (2008). The burden of schizopernia on caregivers. Journal of Pharmacoeconomics, 26 (2), 149-162.

Campbell, M. L. (2013). Nurse to Nurse Perawatan Paliatif. Jakarta: Salemba Medika.
Care, N. C. (2013). Clinical Practice Guidelines for Quality Palliative Care. USA: National Consensus Project for Quality Palliative Care.

Clamor, W. L. (2018). Geriatric Palliative Caregiving Among Caregivers in Metro Manila: Experiences and Assessment of Health Identity and Life Satisfaction. Asia-Pacific Social Science Review 18(2), 164.

Guerrero, J. G. (2019). Palliative nursing care as applied to geriatric: An integrative literature review. Nurs Palliat Care, 2.

Hasan, I. \& Rashid, T. (2016). Clinical Communication, Cancer Patients \& Considerations to Minimize the Challenges. Journal of cancer therapy, 7, 107-113.

Hasanah, N. N., \& Arianti. (2018). Martabat pasien paliatif di rumah sakit pku muhammadiyah gamping. Jurnal Health of Studies, 67.

Ilham, R., Mohammad, S., \& Yusuf, M. N. (2019). Hubungan Tingkat Pengetahuan Dengan Sikap Perawat Tentang Perawatan Paliatif. Jambura Nursing Journal, 100.

Iskandar, Kamil, H., \& Mutiawati, E. (2019). Fenomena Pengalaman Pengasuh dalam Merawat Lansia dengan Penyakit Kronis Rematik di Lembaga Kesejahteraan Sosial Banda Aceh. SEMDI UNAYA, 807-808.

Milligan, S. (2011). Addresing the Spiritual Care Needs of People Near the End Of Life. Nursing Standard/ RCN Publishing, 26 (4), 47-56.

Minanton, S., \& Dr.dr. Dewi, A. M. (2019). Komunikasi Terapeutik Dalam Pelayanan Kanker Dan Paliatif : Kajian Literatur. Jurnal Ilmiah STIKES Citra Delima Bangka Belitung, 4.

Reigada, C., Pais-Ribeiro, J. L., S, A. N., \& Gonçalves, E. (2015). The Caregiver Role in Palliative Care: A Systematic Review of the Literature. Health Care Current Reviews, 3.

Stanley M, P. G. (2006). Buku Ajar Keperawatan Gerontik. Jakarta: EGC.

Wibowo, A., \& Imallah, R. N. (2019). PENGARUH PELATIHAN PALLIATIVE CARE TERHADAP TINGKAT PENGETAHUAN PERAWAT DI IRNA III PAVILIUN CENDRAWASIH RSUP DR. SARDJITO YOGYAKARTA. Unisa Yogya, 6-8. 
Yodang, S. M. (2018). Buku Ajar Keperawatan Paliatif Berdasarkan Kurikulum AIPNI 2015. Jakarta:
CV. Trans Info Media. 